\title{
Incidence of Subclinical Hypothyroidism in Cardiac Surgery Patients. Comparison of Presentation Characteristics, Hospital and Medium-Term Outcomes with Euthyroid Patients
}

\author{
Aarne Jyrala ${ }^{1 \#}$, Nicole M. Gatto ${ }^{2}$, Gregory L. Kay ${ }^{1}$ \\ ${ }^{1}$ Department of Cardiothoracic Surgery, Good Samaritan Hospital, Los Angeles, USA \\ ${ }^{2}$ Department of Epidemiology, UCLA School of Public Health, Los Angeles, USA \\ Email: "lathoracic@hotmail.com
}

Received May 24, 2012; revised June 28, 2012; accepted July 20, 2012

\begin{abstract}
Subclinical hypothyroidism (SCHT) is common, with an occurrence of up to $10 \%$ of the adult population and defined biochemically only by elevated TSH and normal T4. SCHT affects negatively on lipid and carbohydrate metabolism increasing the risk of ischemic heart disease, affects negatively on cardiac performance and have a close correlation with renal function. The aim of this study is to compare presentation characteristics and outcomes between euthyroid pts and pts with SCHT who underwent cardiac surgery. Methods: 474 pts from June 2003 through September 2004 had TSH and T4 measured. 365 pts were euthyroid (Group 1), 41 pts had SCHT (Group 2). Groups were compared by demographics and EuroSCORE (ES) risk profiles. Operative and hospital outcomes were compared as was follow-up mortality up to 96 months. Results: There were more females in Group 2, p $=0.04$, more pts with CHF and number of NYHA III-IV pts $(\mathrm{p}<0.05)$. More $\mathrm{pts}$ in Group 2 had elevated s-crea $(\mathrm{p}<0.0001)$ and atrial fibrillation $(\mathrm{p}=0.007)$. Comparing the Groups by EuroSCORE (ES) showed higher risk scores in Group 2 pts (Additive ES 6.8 vs 8.5 and Logistic ES $12.3 \%$ vs $18.1 \%, p=0.01$ and 0.03$)$. Hospital mortality was higher in Group $2(12.2 \%$ vs $4.1 \%, p=0.04)$ and the number of pts needing extended care was higher in Group $2(\mathrm{p}=0.01)$. Follow up mortality was doubled in Group 2 pts up to 96 months compared to Group $1(\mathrm{p}<0.0001)$. Conclusions: Presentation characteristics and risk scores are different and worse in SCHT pts compared with euthyroid pts. Hospital and follow-up mortality are increased in SCHT pts.
\end{abstract}

Keywords: Hypothyroidism; Cardiac Surgery; Outcomes

\section{Introduction}

After observing a remarkable degree of overlooking and undertreatment of hypothyroid patients (pts) admitted for cardiac surgery a decision was made to have thyroid screening (TSH and T4) of every pt admitted for cardiac surgery in our unit. This report is of the 500 first cardiac surgery pts who had a request of preoperative thyroid screening.

Subclinical hypothyroidism (SCHT) is a common occurrence in the adult population, affecting $4 \%-10 \%$ of the population [1]. It is defined biochemically only and pts with TSH over the upper reference limit and T4 within the normal range are diagnosed having SCHT.

\footnotetext{
*The study was funded by Elma Larsson Foundation, Los Angeles USA and Los Angeles Thoracic and Cardiovascular Foundation, Los Angeles USA.

${ }^{\#}$ Corresponding author.
}

SCHT has many negative effects on different bodily functions: it decreases cardiac performance by decreasing both systolic and diastolic function thus increasing the risk of congestive heart failure (CHF) [2], it increases systemic vascular resistance and lowers preload $[1,3]$, it has negative effect on lipid metabolism increasing the risk of accelerated general and cardiac atherosclerosis with subsequent increased risk to develop ischemic heart disease $[1,3,4]$ and long-term mortality. Increased mortality has recently been reported in pts with heart disease and SCHT [5]. There is a strong association between SCHT and renal function and pts with renal dysfunction have more SCHT than euthyroid pts [6-9]. Thyroid disorders and diabetes mellitus influence each other and diabetes is observed more in SCHT and hypothyroid pts which further increases risk of ischemic heart disease [10].

The aim of this study is to evaluate incidence of SCHT in mixed cardiac surgery population and report the dif- 
ferences in presentation characteristics, EuroSCORE (ES) risk profiles, hospital and medium-term outcomes compared with euthyroid cardiac surgery pts.

\section{Material and Methods}

From June 2003 through September 2004500 pts underwent a cardiac surgery procedure in our unit. Thyroid screening was requested prior to surgery of all these pts. Demographics, operative and hospital course were obtained from hospital charts. ES risk scores were applied using the available on-line calculator [11].

Medium-term (up to 96 months) all-cause mortality was achieved from Social Security Main Death Index [12].

Study was approved by hospital ethics committee and need for consent waived because pts were not contacted.

\section{Operative Technique}

Pts were operated through standard median sternotomy with aortic and right atrial cannulation for cardiopulmonary bypass. Femoral cannulation was used when indicated. Operation was performed in moderate hypothermia to $34^{\circ} \mathrm{C}$. Antegrade and retrograde cold whole blood cardioplegia was used to maintain cardiac standstill and for myocardial protection.

\section{Statistical Analysis}

Mean values of EuroSCORE additive (AES) and logistic (LES) were calculated and categories were created so as to divide patients into low- (AES $\leq 6$; LES $\leq 25 \%$ ) and high-risk groups (AES $>6$; LES $>25 \%$ ). Length of stay in the hospital (LOS) and intensive care unit (ICU) (both in days) were used in their linear form and dichotomized ( $\leq 10$ days versus $>10$ days for hospital stay; $\leq 2$ days versus $>2$ days for ICU stay).

Demographic factors, ES variables, operative characteristics, surgical outcomes and measures of thyroid function were summarized by groups of patients by thyroid function status. Variables were compared between groups of patients using t-tests (for continuous variables) and $\chi^{2}$ tests (for categorical variables), and a p-value $<0.05$ indicated the difference was statistically significant. Factors that these univariate analyses identified as differing between groups of patients were entered into a multivariable logistic regression models to further identify those that were significant independently associated with thyroid status. Preliminary models examined variables by categories: demographic and baseline factors, EuroSCORE variables, operative factors and outcome variables. Only variables which were associated with thyroid status at $\mathrm{p}<$ 0.05 were retained in final models. Odds ratios (ORs) and $95 \%$ confidence intervals $(95 \% \mathrm{CI})$ were estimated from the models comparing patients with subclinical hy- pothyroid to euthyroid pts. Hospital mortality was no longer related to thyroid status when demographic and baseline factors and EuroSCORE variables that were independent correlates were included in our initial models. All analyses used SAS version 9.1 (SAS Institute Inc., Cary, NC, USA.).

\section{Results}

There were 26 pts with no documentation of preoperative thyroid tests. Pts with known hypothyroidism and medication $(n=68)$ were excluded leaving 406 pts for further analysis.

$365(89.9 \%)$ pts (Group 1) were euthyroid by laboratory tests. $41(10.1 \%)$ pts (Group 2) had SCHT with elevated TSH $(>5.0 \mathrm{mIU} / \mathrm{l})$ and $\mathrm{T} 4$ within normal range (5.0 - $11.0 \mathrm{mcg} / \mathrm{dl})$. One pt had unknown overt hypothyroidism (excluded). Operation was delayed and done successfully when the pt was euthryroid.

Altogether 109 pts of 474 pts $(23.0 \%)$ had a thyroid disorder. $68(14.3 \%)$ had overt hypothyroidism and 41 (8.6\%) had SCHT.

Comparing demographic data reveals statistically significant differences (higher in Group 2) in number of females $(\mathrm{p}=0.04$, OR $2.19,95 \% \mathrm{CI} 1.07-4.46)$ in pts with congestive heart failure (CHF) $(\mathrm{p}=0.02$, OR 2.21, $95 \%$ CI 1.17 - 4.47), in pts with atrial fibrillation (AF) (p $=0.007$, OR $4.11,95 \% \mathrm{CI} 1.56-10.85)$, NYHA class $(\mathrm{p}$ $=0.0006)$ number of NYHA III-IV pts $(p=0.005)$, pts with high s-creatinine levels $(\mathrm{p}<0.0001$, OR 1.46, $95 \%$ CI 1.23 - 1.73). There was no difference in the main admitting diagnosis between the Groups. Both AES and LES were considerably higher in Group 2 pts (AES $8.5 \pm$ 4.0 vs $6.8 \pm 4.0, \mathrm{p}=0.01$, OR $1.11,95 \% \mathrm{CI} 1.03-1.20$ and LES $18.1 \pm 18.1$ vs $12.3 \pm 15.2, \mathrm{p}=0.03$, OR 1.02 , 95\%CI 1.01 - 1.04). Details are summarized in Table 1.

ES variables showed more females in Group $2(\mathrm{p}=$ $0.04)$. Statistically significant differences were noted in number of pts with s-crea $>2.2 \mathrm{mg} / \mathrm{dl}(\mathrm{p}=0.02)$, pts in critical condition $(\mathrm{p}=0.02)$, and in pts with pulmonary artery systolic pressure $>60 \mathrm{mmHg}(\mathrm{p}=0.01)$. All these besides pts with high s-crea were correlated to thyroid status by multivariate analysis. Details are summarized in Table 2.

There was only one operative death in Group 1 and none in Group 2. Operative details were remarkably similar as well as the need for IABP support. Group 2 pts needed more often inotropic support after CPB (12/29.3\% vs $57 / 15.6 \%, p=0.04)$ and for longer duration $(5.1 \pm 4.0$ days vs $3.3 \pm 2.5$ days, $p=0.05$ ). Details are summarized in Table 3. Hospital mortality was significantly higher in Group 2 pts $(4.1 \%$ vs $12.2 \%, \mathrm{p}=0.04)$ but all pts who died in hospital had very high preoperative risk scores: mean AES $12.91 \pm 0.69$ and LES $38.32 \pm 21.95$. All pts 
Table 1. Demographics: Group 1 euthyroid pts, $n=365$, Group 2: pts with subclinical hypothyroidism (TSH > 5.5 $\mathrm{uIU} / \mathrm{ml}$, T4 within reference range) $n=41$.

\begin{tabular}{|c|c|c|c|c|}
\hline Variable & $\begin{array}{c}\text { Group } 1 \\
\mathrm{~m} \pm \mathrm{SD} / \mathrm{n} / \%\end{array}$ & $\begin{array}{c}\text { Group } 2 \\
\mathrm{~m} \pm \mathrm{SD} / \mathrm{n} / \%\end{array}$ & $\mathrm{p}$ & $\mathrm{OR}(95 \% \mathrm{CI})$ \\
\hline Age, years & $67.5 \pm 11.0$ & $66.8 \pm 13.1$ & 0.69 & \\
\hline Females & $134 / 36.7$ & $22 / 53.7$ & 0.04 & $\begin{array}{c}2.19 \\
(1.07-4.46)\end{array}$ \\
\hline BMI & $27.3 \pm 5.6$ & $28.0 \pm 6.5$ & 0.86 & \\
\hline $\mathrm{EF}$ & $0.5 \pm 0.2$ & $0.4 \pm 0.2$ & 0.1 & \\
\hline $\mathrm{EF} \leq 0.5$ & $187 / 51.2$ & $27 / 65.9$ & 0.06 & \\
\hline $\mathrm{CHF}$ & $142 / 38.9$ & $24 / 58.5$ & 0.02 & $\begin{array}{c}2.21 \\
(1.17-4.67)\end{array}$ \\
\hline Diabetics & $147 / 40.3$ & $20 / 48.8$ & 0.29 & \\
\hline Preop AF & $31 / 8.5$ & $9 / 22.0$ & 0.007 & $\begin{array}{c}4.11 \\
(1.56-10.85)\end{array}$ \\
\hline NYHA & $2.9 \pm 0.7$ & $3.3 \pm 0.6$ & 0.0006 & \\
\hline NYHA III-IV pts & $255 / 69.9$ & $37 / 90.2$ & 0.005 & \\
\hline S-crea & $1.3 \pm 1.1$ & $2.4 \pm 2.9$ & $<0.0001$ & $\begin{array}{c}1.46 \\
(1.23-1,73)\end{array}$ \\
\hline \multicolumn{5}{|l|}{ MAIN OP. DG: } \\
\hline CAD & $263 / 72.1$ & $27 / 65.9$ & 0.47 & 1.0 Ref \\
\hline VALVE & $83 / 22.7$ & $11 / 26.8$ & 0.56 & \\
\hline OTHER & $19 / 5.2$ & $3 / 7.3$ & 0.48 & \\
\hline AES & $6.8 \pm 4.0$ & $8.5 \pm 4.0$ & 0.01 & $\begin{array}{c}1.11 \\
(1.03-1.20)\end{array}$ \\
\hline $\mathrm{AES}>6^{*}$ & $182 / 49.9$ & $27 / 65.9$ & 0.05 & \\
\hline LES \% & $12.3 \pm 15.2$ & $18.1 \pm 18.1$ & 0.03 & $\begin{array}{c}1.02 \\
(1.01-1.04)\end{array}$ \\
\hline LES $>25 \% * *$ & $48 / 13.2$ & $9 / 21.9$ & 0.15 & \\
\hline \multicolumn{5}{|c|}{$\begin{array}{l}\text { BMI: body mass index } \mathrm{kg} / \mathrm{m}^{2} \text {, EF: left ventricular ejection fraction, CHF: } \\
\text { congestive heart failure, AF: atrial fibrillation, NYHA: New York Heart } \\
\text { Association functional classification, S-crea: preoperative serum cratinine, } \\
\mathrm{mg} / \mathrm{dl} \text {, CAD: coronary artery disease, AES: additive EuroSCORE, LES } \\
\text { logistic EuroSCORE } \%,{ }^{*} \text { High risk pts, **Very high risk pts. }\end{array}$} \\
\hline \multicolumn{5}{|c|}{ Table 2. EuroSCORE variables. } \\
\hline Variable & $\begin{array}{c}\text { Group } \\
\mathrm{n} / \%\end{array}$ & $\begin{array}{c}\text { Group } 2 \\
\mathrm{n} / \%\end{array}$ & $\mathrm{p}$ & OR $(95 \% \mathrm{CI})$ \\
\hline Age 60 or over & $264 / 72.3$ & $28 / 68.3$ & 0.59 & \\
\hline Females & $134 / 36.8$ & $22 / 53.7$ & 0.04 & $\begin{array}{c}2.19 \\
(1.07-4.46)\end{array}$ \\
\hline COPD & $74 / 20.3$ & $9 / 21.9$ & 0.84 & \\
\hline Atherosclerosis & $93 / 25.5$ & $15 / 36.6$ & 0.14 & \\
\hline Neurol. deficit & $27 / 7.4$ & $1 / 2.4$ & 0.39 & \\
\hline REDO & $33 / 9.0$ & $3 / 7.3$ & 0.94 & \\
\hline $\begin{array}{c}\text { CREA > } 2.2 \\
\mathrm{mg} / \mathrm{dl}\end{array}$ & $30 / 8.2$ & $8 / 19.5$ & 0.02 & - \\
\hline
\end{tabular}

Continued

\begin{tabular}{ccccc}
\hline ENDOC & $6 / 1.6$ & $1 / 2.4$ & 0.53 & \\
CRITICAL & $40 / 11.0$ & $10 / 24.4$ & 0.02 & $\begin{array}{c}2.17 \\
(1.06-4.89)\end{array}$ \\
UNSTABLE AP & $14 / 3.8$ & $3 / 7.3$ & 0.40 & \\
EF 0.3 - 0.5 & $134 / 36.7$ & $21 / 51.2$ & 0.09 & \\
EF $<0.30$ & $46 / 12.6$ & $7 / 17.1$ & 0.57 & \\
AMI & $88 / 24.1$ & $12 / 29.3$ & 0.45 & 3.94 \\
PAP $>$ 60 mmHg & $20 / 5.5$ & $9 / 21.9$ & 0.01 & $(1.62-9.59)$ \\
EMERGENCY & $35 / 9.6$ & $5 / 12.2$ & 0.58 & \\
OTHER* & $117 / 32.1$ & $17 / 41.5$ & 0.22 & \\
AORTA & $4 / 1.1$ & $0 / 0$ & 1 & \\
VSD & $1 / 0.28$ & $0 / 0$ & 1 &
\end{tabular}

COPD: chronic obstructive pulmonary disease, REDO: pt has undergone an earlier cardiac operation, crea: preoperative serum creatinine level in $\mathrm{mg} / \mathrm{dl}$. AP: angina pectoris, EF: left ventricular ejection fraction, AMI: acute myocardial infarction within 90 days before surgery, PAP: pulmonary artery (systolic) pressure, $\mathrm{mmHg}$, VSD: postinfarction ventricular septal defect. *Other surgery than CABG only.

Table 3. Operative details.

\begin{tabular}{cccc}
\hline Variable & Group 1 & Group 2 & $\mathrm{p}$ \\
\hline OP DEATHS & $1 / 0.3$ & 0 & 1 \\
CPB & $121.5 \pm 38.6$ & $123.3 \pm 39.4$ & 0.78 \\
X-CLAMP & $100.4 \pm 34.6$ & $100.9 \pm 33.2$ & 0.99 \\
PROCEDURES: & & & \\
CABG ONLY & $239 / 65.5$ & $25 / 61.0$ & 0.09 \\
AVR + CABG & $33 / 9.0$ & $4 / 9.8$ & 0.78 \\
MVR + CABG & $8 / 4.9$ & $3 / 7.3$ & 0.46 \\
AVR & $2 / 11.5$ & $3 / 7.3$ & 0.60 \\
MVR & $26 / 7.1$ & $2 / 4.9$ & 0.83 \\
MISC & $7 / 1.9$ & $4 / 9.8$ & 0.02 \\
$\begin{array}{c}\text { Peroperative IABP } \\
\text { Inotropes post CPB }\end{array}$ & $97 / 2.5$ & $2 / 4.9$ & 0.69 \\
$\begin{array}{c}\text { Duration of inotropes, } \\
\text { days }\end{array}$ & $3.3 \pm 2.5$ & $5.1 \pm 4.0$ & 0.05 \\
\hline
\end{tabular}

CPB: cardiopulmonary bypass time, minutes, X-CLAMP: aortic crossclamp time, minutes, CABG: coronary artery bypass, AVR: aortic valve replacement, MVR: mitral valve repair or replacement, IABP: intra-aortic balloon pulsation device.

were high-risk pts (AES > 6) and $15(65.2 \%)$ very highrisk pts (LES $>25 \%$ ). The difference in hospital deaths was not correlated to thyroid status. There were no statis- 
tically significant differences in the stay in postoperative ICU or LOS but there was a trend for longer times in Group 2 pts. Postoperative incidence of AF and renal failure did not differ. More pts in Group 2 had to be transferred to another institution for rehabilitation or further care $(12.0 \%$ vs $27.8 \%, p=0.01)$ Details are summarized in Table 4.

Mean follow-up time for hospital survivors was similar as was the range of follow-up months. A highly statistically significant difference (higher in Group $2 \mathrm{pts}$ ) was noted in follow-up all-cause mortality $(29.5 \%$ vs $63.9 \%, \mathrm{p}<0.0001)$. Details are summarized in Table 5.

$7 \mathrm{pts}$ in Group $1 \mathrm{had}$ TSH $>10 \mathrm{mIU} / 1$ and there are suggestions that these pts should be treated with levothyroxine [13]. All these pts were started on levothyroxine postoperatively. $3 \mathrm{pts}$ of these were alive at the end of follow-up.

Table 4. Hospital outcomes.

\begin{tabular}{cccc}
\hline & $\begin{array}{c}\text { Group } 1 \\
\mathrm{n} / \%\end{array}$ & $\begin{array}{c}\text { Group } 2 \\
\mathrm{n} / \%\end{array}$ & $\mathrm{p}$ \\
\hline Hospital mortality & $15 / 4.1$ & $5 / 12.2$ & 0.04 \\
ICU, DAYS & $3.2 \pm 6.5$ & $5.1 \pm 10.3$ & 0.09 \\
ICU > 2 DAYS & $78 / 21.4$ & $12 / 29.3$ & 0.24 \\
LOS, DAYS & $11.1 \pm 10.3$ & $14.4 / 12.7$ & 0.06 \\
LOS $>10$ DAYS & $117 / 32.1$ & $18 / 43.9$ & 0.16 \\
POSTOP AF* & $50 / 14.8$ & $3 / 9.38$ & 0.60 \\
POSTOP RF** & $46 / 13.7$ & $8 / 25.8$ & 0.11 \\
\hline DISCH TO HOSP*** & $42 / 12.0$ & $10 / 27.8$ & 0.01 \\
\hline
\end{tabular}

ICU: days in the postoperative intensive care unit, LOS: days of hospitalization, AF: atrial fibrillation, RF:renal failure, ${ }^{*}$ From pts with preoperative sinus rhythm 1:n $=337,2: \mathrm{n}=32$. ${ }^{*}$ From pts with preoperative s-crea $<$ $2.25 \mathrm{mg} / \mathrm{dl}, 1: \mathrm{n}=335,2: \mathrm{n}=31$. Renal failure: increase of s-crea $>2.2 \mathrm{mg} / \mathrm{dl}$ with or without need of renal replacement therapy during hospitalization. ***Calculated from hospital survivors Group $1 \mathrm{n}=349$, Group $2 \mathrm{n}=36$.

Table 5. Follow-up of hospital survivors. Group $1 \mathbf{n}=349$, Group 2 n = 36 .

\begin{tabular}{cccc}
\hline & Group 1 & Group 2 & $\mathrm{p}$ \\
\hline Mean f-u time, months & $40.0 \pm 28.2$ & $38.2 \pm 32.9$ & 1 \\
Range, months & $1-96$ & $1-96$ & - \\
F-u all-cause mortality & $103 / 29.5 \%$ & $23 / 63.9 \%$ & $<0.0001$ \\
\hline
\end{tabular}

F-u: follow-up.

\section{Discussion}

SCHT is a common disorder affecting $4 \%-10 \%$ of the adult population [1]. It is defined biochemically only and pts having TSH above the reference limit and T4 within the reference limit are suffering from SCHT. Although known for about 40 years there still are controversies associated with treatment $[13,14]$ and its effect on bodily functions. It is agreed that SCHT represents a mild form of tissue hypothyroidism and its effects are basically similar to those seen in overt hypothyroidism but weaker $[14,15]$. There are no reports available where demographic data and ES risk scores have been compared in cardiac surgery pts with and without SCHT. It is quite obvious from our series that SCHT pts have higher burden of comorbidities than pts without which has an effect on hospital mortality, need for extended care postoperatively and follow-up mortality as well. SCHT affects cardiac performance in several ways. It increases afterload and decreases preload with reduction of stroke volume and cardiac output [16] and has negative effects on systolic and diastolic function thus increasing the risk of development of CHF. The negative effects may be mitigated with adequate levothyroxine treatment $[2,17]$. Rodondi et al. [16] reported a 12 year follow up of adults over 65 years of age and at the end $24 \%$ had developed SCHT. Risk of congestive heart failure was increased in pts with TSH $>10 \mathrm{mU} / 1$ and was considered a potential modifiable risk factor for CHF. In our series pts with SCHT had a $58.5 \%$ incidence of CHF and euthyroid pts had an incidence of $38.9 \%, p=0.02$, indicating that pts with SCHT and heart disease have increased risk of developing CHF than euthyroid pts with heart disease.

In our series, occurrence of diabetes was marginally higher in pts with SCHT (48.8\% vs $40.0 \%)$ Recent reports $[18,19]$ describe close relationship between SCHT and diabetes specially with Type 1 diabetes. It is very likely that a combination of SCHT and diabetes has enhanced risk for deleterious effects on cardiovascular and metabolic functions but may be modifiable with levothyroxine treatment. A recent review by Hage, Zantout and Azar [10] gives in depth information about the impact of thyroid dysfunction on glucose control and on diabetes management.

Increased incidence of preoperative AF in pts with SCHT has not been reported earlier but in our series the incidence is $22.0 \%$ vs $8.5 \%$ with a p-value of 0.007 and correlated to the thyroid status (OR 4.11,95\% 1.56 10.85).

Pts with preoperative AF in our series are not older than pts without and the risk scores are similar. Also age and risk scores are similar between SCHT pts with AF and euthyroid pts with AF. This finding should be validated by larger cohorts of pts. Postoperative AF has been 
reported to be higher in SCHT pts after CABG surgery [20] but was not observed in our series. SCHT has a close relationship with kidney function [7] and pts with chronic kidney disease have more SCHT than pts with normal kidneys $[6,8,9]$. Any degree of kidney failure has an impact on post cardiac surgery follow-up mortality so the finding of a remarkable increase of preoperative s-crea levels in pts with SCHT have a impact on the observed higher follow-up mortality in SCHT pts. The effect of treatment with levothyroxine in the postoperative period has not been evaluated but should be done. Increase of postoperative renal failure in SCHT pts was not observed in our series. It is known that SCHT has a negative influence on lipid metabolism increasing the risk of coronary heart disease [2,21-23] but the results are somewhat conflicting. Whether treatment with levothyroxine may prevent or decrease cardiovascular ischemic events is not known. In our series the incidence of CAD as the main operative diagnosis did not differ between the Groups so the SCHT effect on development of CAD is probably quite weak.

Iervasi et al. [5] has recently reported increased cardiac and all-cause mortality in pts with SCHT and mixed cardiac diseases with a mean follow-up of 32 months and concluded that mildly altered thyroid status is associated with increased mortality in pts with cardiac disease. This is also evident in our series with a highly significant $(\mathrm{p}<$ 0.0001 ) difference between the Groups in all-cause follow-up mortality.

\section{Drawbacks}

This is a retrospective observational study with rather limited number of pts. We have no knowledge of postoperative thyroid status and whether some of pts developed overt hypothyroidism or the adequacy of treatment of pts who were started on replacement therapy postoperatively.

\section{Conclusions}

In our opinion it is prudent to screen all cardiac surgery pts for thyroid disorders since $23 \%$ of pts in this series had a thyroid disorder.

SCHT in cardiac surgery pts should be regarded as a marker for pts with increased number of comorbidities with higher risk scores and subsequent higher hospital and follow-up mortality.

The question whether levothyroxine treatment [24] would modify cardiovascular risk scores preoperatively and outcomes in SCHT pts should be evaluated.

\section{REFERENCES}

[1] B. Biondi and D. S. Cooper, "The Clinical Significance of
Subclinical Thyroid Dysfunction," Endocrine Reviews, Vol. 29, No. 1, 2008, pp. 76-131.

doi:10.1210/er.2006-0043

[2] F. Monzani, V. Di Bello, N. Caraccio, A. Bertini, D. Giorgi, C. Giusti and E. Ferrannini, "Effect of Levothyroxine on Cardiac Function and Structure in Subclinical Hypothyroidism: A Double-Blind, Placebo-Controlled Study," The Journal of Clinical Endocrinology \& Metabolism, Vol. 86, No. 3, 2001, pp. 1110-1115. doi:10.1210/jc.86.3.1110

[3] N. Rodondi, A. B. Newman, E. Vittinghoff, N. de Rekeneire, S. Satterfield, T. B. Harris and D. C. Bauer, "Subclinical Hypothyroidism and the Risk of Heart Failure, Other Cardiovascular Events, and Death," Archives of Internal Medicine, Vol. 165, No. 21, 2005, pp. 2460-2466. doi:10.1001/archinte.165.21.2460

[4] J. P. Walsh, A. P. Bremner, M. K. Bulsara, P. O’Leary, P. J. Leedman, P. Feddema and V. Michelangeli, "Subclinical Thyroid Dysfunction as a Risk Factor for Cardiovascular Disease," Archives of Internal Medicine, Vol. 165, No. 21, 2005, pp. 2467-2472. doi:10.1001/archinte.165.21.2467

[5] G. Iervasi, S. Molinaro, P. Landi, M. C. Taddei, E. Galli, F. Mariani, A. L'Abbate and A. Pingitore, "Association between Increased Mortality and Mild Thyroid Dysfunction in Cardiac Patients," Archives of Internal Medicine, Vol. 167, No. 14, 2007, pp. 1526-1532. doi:10.1001/archinte.167.14.1526

[6] M. Chonchol, G. Lippi, G. Salvagno, G. Zoppini, M. Muggeo and G. Targher, "Prevalence of Subclinical Hypothyroidism in Patients with Chronic Kidney Disease," Clinical Journal of the American Society of Nephrology, Vol. 3, No. 5, 2008, pp. 1296-1300. doi: $102215 /$ CJN.00800208

[7] P. Iglesias and J. J. diez, "Thyroid Dysfunction and Kidney Disease," European Journal of Endocrinology, Vol. 160, No. 4, 2008, pp. 503-515. doi:101530/EJE-08-0837

[8] B. O. Åsvold, T. Bjøro and L. J. Vatten, "Association of Thyroid Function with Estimated Glomerular Filtration Rate in a Population-Based Study: The HUNT Study," European Journal of Endocrinology, Vol. 164, No. 1, 2011, pp. 101-105. doi:101530/EJE-10-0705

[9] J. C. Lo, G. M. Chertow, A. S. Go and C.-Y. Hsu, "Increased Prevalence of Subclinical and Clinical Hypothyroidism in Persons with Chronic Kidney Disease," Kidney International, Vol. 67, No. 6, 2005, pp. 1047-1052. doi:10.1111/j.1523-1755.2005.00169.x

[10] M. Hage, M. S. Zantout and S. T. Azar, "Thyroid Disorders and Diabetes Mellitus," Journal of Thyroid Research, Vol. 2011, 2011, pp. 1-7. doi:10.4061/2011/4393463

[11] EuroSCORE, "NEW! EuroSCORE II," 2011. http://www.euroscore.org

[12] Social Security Death Master File, "Important Notice: Change in Public Death Master File Records," 2011. http://www.ssdmf.com

[13] E. N. Pearce, "In People with Subclinical Hypothyroidism, TSH $>10 \mathrm{mIU} / 1$ May Predict Increased Risk of Coronary Heart Disease and Related Mortality," Evidence-Based Medicine, Vol. 16, No. 1, 2011, pp. 31-32. 
[14] M. I. Surks, E. Ortiz, G. H. Daniels, C. T. Sawin, N. F. Col, R. H. Cobin, J. A. Franklyn, J. M. Hershman, K. D. Burman, M. A. Denke, C. Gorman, R. S. Cooper and N. J. Weissman, "Subclinical Thyroid Disease: Scientific Review and Guidelines for Diagnosis and Management," The Journal of American Medical Association, Vol. 291, No. 2, 2004, pp. 228-238. doi:10.1001/jama.291.2.228

[15] M. T. McDermott and E. C. Ridgway, "Subclinical Hypothyroidism Is Mild Thyroid Failure and Should Be Treated," The Journal of Clinical Endocrinology \& Metabolism, Vol. 86, No. 10, 2001, pp. 4585-4590. doi:101210/jc86.10.4585

[16] N. Rodondi, D. C. Bauer, A. R. Cappola, J. Cornuz, J. Robbins, L. P. Fried, et al., "Subclinical Thyroid Dysfunction, Cardiac Function and the Risk of Heart Failure: The Cardiovascular Health Study," Journal of the American College of Cardiology, Vol. 52, No. 14, 2008, pp. 1152-1159. doi:10.1016/j.jacc.2008.07.009

[17] M. Yazici, S. Gorgulu, Y. Sertbas, E. Erbilen, S. Albayark, O. Yidiz and C. Uyan, "Effects of Thyroxin Therapy on Cardiac Function in Patients with Subclinical Hypothyroidism: Index of Myocardial Performance in the Evaluation of Left Ventricular Function," International Journal of Cardiology, Vol. 95, No. 2, 2004, pp. 135-143. doi:10.1016/j.ijcard.2003.05.015

[18] K. Ashizawa, M. Imaizumi, T. Usa, T. Tominaga, N. Sera, A. Hida, et al., "Metabolic Cardiovascular Disease Risk Factors and Their Clustering in Subclinical Hypothyroidism," Clinical Endocrinology, Vol. 72, No. 5, 2010, pp. 689-695. doi:10111/j.1365-2265.2009.03697.x

[19] R. Kadiyala, R. Peter and O. E. Okosieme, "Thyroid Dysfunction in Patients with Diabetes: Clinical Implications and Screening Strategies," International Journal of Clinical Practice, Vol. 64, No. 8, 2010, pp. 1130-1139.
doi:10.1111/j.1742-1241.2010.02376.X

[20] J. Y. Park, J. W. Yoon, K. I. Kim, Y. J. Lee, K. W. Kim, S. H. Choi, S. Lim, D. J. Choi, K.-H. Park, J. H. Choh, H. C. Jang, S. Y. Kim, B. Y. Cho and C. Lim, "Subclinical Hypothyroidism May Increase the Risk of Transient Atrial Fibrillation after Coronary Artery Bypass Grafting," The Annals of Thoracic Surgery, Vol. 87, No. 6, 2009, pp. 1846-1852. doi:10.1016/j.athoracsurg.2009.03.032

[21] N. Rodondi, W. P. den Elzen, D. C. Bauer, A. R. Cappola, S. Razvi, J. P. Walsh, B. O. Asvold, G. Iervasi, M. Imaizumi, T. H. Collet, A. Bremner, P. Maisonneuve, J. A. Sgarbi, K. T. Khaw, M. P. Vanderpump, A. B. Newman, J. Cornuz, J. A. Franklyn, R. G. Westendorp, E. Vittinghoff, J. Gussekloo and Thyroid Studies Collaboration, "Subclinical Hypothyroidism and the Risk of Coronary Heart Disease and Mortality," The Journal of American Medical Association, Vol. 304, No. 12, 2010, pp. 13651374. doi:101001/jama.2010.1361

[22] N. Ochs, R. Auer, D. C. Bauer, D. Nanchen, J. Gusselkoo, J. Cornuz and N. Rodondi, "Meta-Analysis: Subclinical Thyroid Dysfunction and the Risk for Coronary Heart Disease and Mortality," Annals of Internal Medicine, Vol. 148, No. 11, 2008, pp. 832-845.

[23] S. Razvi, A. Shakoor, M. Vanderpump, J. U. Weaver and S. H. S. Pearce, "The Influence of Age on the Relationship between Subclinical Hypothyroidism and Ischemic Heart Disease: A Meta-Analysis," The Journal of Clinical Endocrinology \& Metabolism, Vol. 93, No. 8, 2008, pp. 2998-3007. doi:10.1210/jc.2008-0167

[24] I. A. Weiss, N. Bloomgarden and W. H. Frishman, "Subclinical Hypothyroidism and Cardiovascular Risk: Recommendations for Treatment," Cardiology in Review, Vol. 19, No. 6, 2011, pp. 291-299. doi:10.1097/CRD.0b013e318227df87 